\title{
Sexual dimorphism and dichromatism in Steere's Liocichla (Liocichla steerii)
}

\author{
Herman L. Mays Jr., ${ }^{1}$ Stéphanie M. Doucet, ${ }^{1}$ Cheng-Te Yao, ${ }^{2,3}$ and Hsiao-Wei Yuan ${ }^{4,5}$ \\ ${ }^{1}$ Department of Biological Sciences, Auburn University, Auburn, AL, 36349, USA \\ ${ }^{2}$ Endemic Species Research Institute, Council of Agriculture, Jiji, Taiwan \\ ${ }^{3}$ Department of Life Sciences, National Cheng Kung University, Tainan, Taiwan \\ ${ }^{4}$ School of Forestry and Resource Conservation, National Taiwan University, Taipei, Taiwan
}

Received 27 March 2006; accepted 7 July 2006

\begin{abstract}
Although sexual differences in birds can be extreme, differences between males and females in body size and plumage color are more subtle in many species. We used a genetic-based approach to determine the sex of male and female Steere's Liocichla (Liocichla steerii) and examine the degree of size dimorphism and plumage dichromatism in this apparently monomorphic species. We found that males were significantly larger than females. In addition, Steere's Liocichla have a prominent yellow plumage patch on the lores that was significantly larger in males than females for both live birds and museum specimens. We also used reflectance spectrometry to quantify the color of the yellow-green breast feathers of Steere's Liocichla and found no significant differences between males and females in brightness, intensity, saturation, or hue. However, females tended to have brighter breast plumage, particularly at long wavelengths. Collectively, these color variables were useful in discriminating birds according to sex when used in a discriminant function analysis. Our study suggests that sexual selection may be more widespread than once assumed, even among birds considered monomorphic, and emphasizes the need for additional data from tropical and subtropical species.
\end{abstract}

\section{SINOPSIS. Dimorfismo sexual y dicromatismo en Liocichla steerii}

Aunque las diferencias sexuales entre algunas especies puede ser estrechas, un muchas de estas las diferencias corporales entre los sexos pudiera ser sutiles. Abordamos el asunto basados en genética para determinar el sexo en Liocichla steerii y examinamos el grado de dimorfismo sexual y dicromatismo en el plumaje en esta especie la cual aparentemente es monomórfica. Encontramos que los machos eran significativamente de mayor tamaño que las hembras. Además encontramos en los machos un parcho amarillo en los lores significativamente más grande que en las hembras, tanto en aves del estado silvestre como en pieles de museos. Usamos espectrometría para cuantificar el color de las plumas verde-amarillentas del pecho de las aves y no encontramos diferencias significativas entre los sexos, con respecto a la brillantez, insensidad, saturación o matiz color. Sin embargo, las hembras tuvieron la tendencia a tener el plumaje más brillante en el pecho particularmente en el espectro de onda larga. Colectivamente, estas variables de color fueron útiles para discriminar entre el sexo de las aves, particularmente cuando fueron examinadas utilizando un análisis discriminante de funciones. Nuestro estudio sugiere que la selección sexual pudiera estar más ampliamente distribuida que lo previamente asumido, aún en aves consideradas monomórficas. Además el trabajo enfatiza la necesidad de llevar a cabo estudios adicionales, de este tipo, tanto en especies del trópico como de la zona templada.

Key words: plumage color, sexual dichromatism, sexual dimorphism, Steere's Liocichla

In many avian species, differences between males and females in size and plumage color are extreme. For example, male Western Capercaillie (Tetrao urogallus) can be twice as large as females (Milonoff and Linden 1989, de Juana 1994) and male Great Bustards (Otis tarda) more than three times the size of females (Collar 1996). Plumage coloration of male and female Eclectus

\footnotetext{
${ }^{5}$ Corresponding author. Email: hwyuan@ntu. edu.tw
}

Parrots (Eclectus roratus) is so different they were originally considered separate species (Heinsohn et al. 2005). These dramatic examples of sexual dimorphism notwithstanding, most passerines (69\%) have historically been considered sexually monomorphic (Barraclough and Harvey 1995). However, for many so-called monomorphic species, there may be subtle differences between males and females in plumage color and size. In a survey of plumage color of passerines previously identified as monochromatic, Eaton (2005) found that, to varying degrees, most species were sexually dichromatic. Eaton and 
Lanyon (2003) suggested that this may also be true for many nonpasserines.

The degree of sexual dimorphism may be an indicator of the strength of sexual selection (Badyaev and Hill 2003). Within species, studies of dimorphism can therefore serve as an initial assessment of the strength of sexual selection and help identify traits likely to be the subject of selection. Among species, understanding the degree and taxonomic distribution of sexual dimorphism can provide a better understanding of the evolutionary causes and consequences of sexual selection. Further documentation of the ubiquity and degree of sexual differences in birds, particularly among underrepresented taxa, will contribute to a better understanding of the different selective forces acting on the sexes and facilitate the development of more inclusive comparative analyses.

We examined the extent of sexual differences in body size and plumage in Steere's Liocichla (Liocichla steerii, Family Timaliidae). Steere's Liocichla is endemic to the island of Taiwan and found in montane forests, typically associated with forest-edge habitat and secondary growth. Like many open-cup nesting tropical birds (Stutchbury and Morton 2001), Steere's Liocichla are socially monogamous, exhibit biparental care, and have relatively small clutches of 2-3 eggs (Lo 1987, Fang 2005, Mays et al. 2005). Unlike many temperate species, longterm pair bonds are maintained, and males and females engage in antiphonal duets throughout the year (Lo 1987, Fang 2005, Mays et al. 2005). Superficially, male and female Steere's Liocichla are indistinguishable, even in the hand (Lo 1987, MacKinnon and Phillipps 2000). However, to date, there has been no quantitative analysis of sexual differences in either body size or plumage color for this species and little is known about sexual dimorphism among timaliid babblers in general (MacKinnon and Phillipps 2000, Cibois 2003, Rasmussen and Anderton 2005).

\section{METHODS}

We studied Steere's Liocichla in central Taiwan from May to August 2003 and 2004 at the National Taiwan University Meifeng Horticultural Farm in Nantou County, Taiwan $\left(24^{\circ} 05^{\prime} \mathrm{N}, 121^{\circ} 10^{\prime} \mathrm{E}\right)$. This site includes a variety of habitat types, ranging from human- disturbed habitat to comparatively undisturbed native forest.

During the breeding season (mid-May to late August), we captured birds using mist nets. Captured birds were marked with a unique combination of three colored leg bands and a metal numbered band issued by the Taiwan Forest Bureau (Taipei, Taiwan). For each bird we recorded the length of the right tarsus, unflattened wing chord, tail length, length of the exposed culmen, and mass. Steere's Liocichla have a bright yellow, slightly crescent to ovalshaped plumage patch between the eye and the bill and we also measured the length of this patch along its longest axis on the right lore. Measurements were made either with a measured wing rule (wing chord and tail length) or analog calipers (tarsus, culmen, and facial patch length). Mass was measured by resting a restrained bird on a digital scale (JS-1000, JScale USA, Phoenix, AZ). We also collected 4-6 breast feathers from the center of the breast and stored them in sealed microcentrifuge tubes at room temperature and in the dark for later analysis.

Blood was collected from each individual via either brachial or tarsal venipuncture. Approximately 100-200 $\mu$ l of whole blood was collected and stored in 250-500 $\mu \mathrm{l}$ of lysis buffer (Seutin et al. 1991) depending on the amount of blood obtained for each sample. Blood was stored at approximately $20^{\circ} \mathrm{C}$ in the field and later at $-20^{\circ} \mathrm{C}$ in the laboratory.

Genetic sexing methods. Whole genomic DNA was extracted from blood samples collected in the field using standard phenolchloroform-isoamyl alcohol (PCI)-based extractions followed by ethanol precipitation and washes. After extraction, genomic DNA was stored at $-20^{\circ} \mathrm{C}$ in $1 \mathrm{xTE}(\mathrm{pH} 7.8)$.

Genetic sexing was performed using polymerase chain reaction (PCR) amplification of an intron in the sex-linked chromobox-helicaseDNA-binding gene (CHD). This intron differs in length between the $\mathrm{W}$ and $\mathrm{Z}$ avian sex chromosomes and thus can be used as a marker for genetic sex determination (Griffiths et al. 1998). PCR was conducted in $25 \mu \mathrm{l}$ reactions with $5 \mu \mathrm{l}$ of diluted genomic DNA (1:10 to $1: 2$ depending on initial concentration), $0.8 \mu \mathrm{M}$ of $\mathrm{P} 2$ primer, $0.8 \mu \mathrm{M}$ of $\mathrm{P} 8$ primer, dNTPs at a final concentration of $0.05 \mathrm{mM}$ each (Promega , Madison, WI), $1 \mathrm{mM} \mathrm{MgCl}$, $1 \times$ PCR buffer and $0.1 \mu$ l AmpliTaq ${ }^{\text {TM }}$ DNA 
polymerase (Applied Biosystems, Foster City, CA). Thermal cycling was performed on a PTC100 thermocycler (MJ Research, Watertown, MA) under the following conditions: $94^{\circ} \mathrm{C}$ for $90 \mathrm{~s}$, followed by 30 cycles of $48^{\circ} \mathrm{C}$ for $45 \mathrm{~s}$, $72^{\circ} \mathrm{C}$ for $45 \mathrm{~s}$ and $94^{\circ} \mathrm{C}$ for $30 \mathrm{~s}$ and a final cycle of $48^{\circ} \mathrm{C}$ for $1 \mathrm{~min}$ and $72^{\circ} \mathrm{C}$ for $5 \mathrm{~min}$. PCR products from these reactions were visualized via electrophoresis using 1.8\% agarose gels. Images of gels were digitally recorded using a ChemiImager 4400 gel documentation system (Alpha Innotech Corporation, San Leandro, CA). The sex of each individual was determined by visual inspection of digital images obtained from gels. Individuals with two bands were recorded as female, with these bands corresponding to alleles on the $\mathrm{W}$ and $\mathrm{Z}$ avian sex chromosomes. Individuals with one band, corresponding to the homozygous $\mathrm{Z} / \mathrm{Z}$ genotype, were recorded as males (Griffiths et al. 1998).

spectrometry. We measured the reflectance of feathers using an S2000 Spectrometer and DHT 2000 deuterium halogen tungsten light source (Ocean Optics, Dunedin, FL). We taped feathers onto matte black cardboard in an overlapping fashion to approximate placement on the bird's body. We obtained readings with a fiber-optic, metal- encased probe mounted in a black rubber holder that maintained the probe at a fixed perpendicular angle approximately $5 \mathrm{~nm}$ from the measurement surface and excluded external light. We collected five readings per individual and each reading consisted of an average of 20 spectra taken in rapid succession. Reflectance was calculated as percent reflectance relative to a Spectralon white standard (Labsphere, North Sutton, NH), a nearly perfect reflector.

Four colorimetric variables were calculated from the spectrophotometric data to summarize variation in color (Montgomerie 2006). We calculated brightness as the sum of percent reflectance values from within the visible spectrum of birds $(300-700 \mathrm{~nm}$; Cuthill et al. 2000, Hart 2001). Intensity was calculated as the maximum reflectance reached, and saturation as the difference between the maximum and the minimum reflectance divided by the total reflectance. We calculated hue as the wavelength at which reflectance reached $50 \%$ of the maximum reflectance. Analysis of individual color variables in relation to sex was conducted using $t$-tests. We also conducted a multivariate analysis com- bining all four color variables into a predictive discriminant function analysis (DFA) with sex as the classification variable (McGarigal et al. 2000). To assess the classification accuracy of the multivariate DFA, we calculated Cohen's Kappa (Titus et al. 1984).

Statistical analyses were performed using SPSS for Windows (version 11.5.0; SPSS Inc. 2002) for morphology analyses and JMP for Mac (version 5.0.1.2; SAS Institute Inc., 2003) for all color analyses. Values are given as mean $\pm 1 \mathrm{SE}$, and alpha levels for statistical significance were set at $P<0.05$.

\section{RESULTS}

No character deviated significantly from a normal distribution (Kolmogorov-Smirnov Tests, $P>0.05$ for all tests) and we detected no significant differences in variance between males and females for any measure (Levene's Test for Equality of Variances, $P>0.05$ for all tests). Many variables were significantly correlated with each other (Table 1).

We found that males had significantly greater mass and longer right tarsi, wing chords, tails, and yellow facial patches (Table 2). However, males and females did not differ in bill length (Table 2). Our measures of bill length and the length of the yellow facial patch differed significantly for birds measured in 2003 and 2004 (Table 2), but there were no significant yearby-sex interaction effects for any morphological variable (Table 2$)$.

To determine if the size of the yellow facial patch was proportionately larger in males, we scaled length of the facial patch by dividing patch length by tarsus length. Tarsus length provides a good approximation of overall skeletal body size in birds (Rising and Somers 1989) and is, therefore, a useful single metric to control for body size. Because we found differences between years in patch size (Table 2), we conducted separate tests for each year. Mean patch length relative to tarsus length was greater for males $(\bar{x}=0.29 \pm 0.01, N=9)$ than females $(\bar{x}=$ $0.23 \pm 0.08, N=8)$ in 2003 , but the difference was not significant $\left(t_{15}=2.08, P=0.06\right)$. We found no difference between males $(\bar{x}=0.26 \pm$ $0.01, N=12)$ and females $(\bar{x}=0.26 \pm 0.01$, $N=16)$ in patch length relative to tarsus length in $2004\left(t_{26}=0.08, P=0.94\right)$. 
Table 1. Pearson correlations for morphological measures on male and female Steere's Liocichla combined.

\begin{tabular}{|c|c|c|c|c|c|c|}
\hline & Bill & Tarsus & Wing & Patch & Tail & $\overline{\text { Mass }}$ \\
\hline \multirow[t]{3}{*}{$\overline{\text { Bill }}$} & 1 & & & & & \\
\hline & - & & & & & \\
\hline & 45 & & & & & \\
\hline \multirow[t]{3}{*}{ Tarsus } & 0.12 & 1 & & & & \\
\hline & 0.44 & - & & & & \\
\hline & 44 & 45 & & & & \\
\hline \multirow[t]{3}{*}{ Wing } & 0.05 & 0.17 & 1 & & & \\
\hline & 0.74 & 0.26 & - & & & \\
\hline & 45 & 45 & 46 & & & \\
\hline \multirow[t]{3}{*}{ Patch } & $0.56^{* * *}$ & 0.30* & $0.30^{*}$ & 1 & & \\
\hline & $<0.001$ & 0.04 & 0.04 & - & & \\
\hline & 45 & 45 & 46 & 46 & & \\
\hline \multirow[t]{3}{*}{ Tail } & 0.04 & 0.16 & $0.39^{* *}$ & $0.30^{*}$ & 1 & \\
\hline & 0.78 & 0.29 & $<0.01$ & 0.04 & - & \\
\hline & 44 & 44 & 45 & 45 & 45 & \\
\hline \multirow[t]{3}{*}{ Mass } & -0.03 & $0.37^{*}$ & 0.21 & 0.25 & $0.32^{*}$ & 1 \\
\hline & 0.85 & 0.02 & 0.17 & 0.11 & 0.04 & - \\
\hline & 42 & 42 & 43 & 43 & 42 & 43 \\
\hline
\end{tabular}

In each cell, the Pearson coefficient is given first, followed by the $P$ value and the sample size.

${ }^{*} P<0.05,{ }^{* *} P<0.01,{ }^{* * *} P<0.001$.

We also examined the length of facial patches on museum skins in the Taichung Natural History Museum (Taichung, Taiwan). Patch length was measured blind with respect to sex by covering the identification tags on each specimen. Patch length on the museum skins $(\bar{x}=5.80 \pm$ $0.23 \mathrm{~mm}, N=24$ ) was significantly shorter than on live birds $(\bar{x}=7.93 \pm 0.15 \mathrm{~mm}$, $\left.N=46 ; t_{68}=8.17, P<0.001\right)$. However, the relative difference between males and females remained for museum skins, with males $(\bar{x}=$ $6.16 \pm 0.26 \mathrm{~mm} ; N=15$ ) having significantly longer facial patches than females $(\bar{x}=5.20 \pm$ $\left.0.35 \mathrm{~mm}, N=9 ; t_{22}=2.22, P=0.04\right)$.

Although females tended to have higher overall reflectance values (Fig. 1), there were no significant differences $(P \geq 0.12)$ between males $(N=14)$ and females $(N=21)$ for any colorimetric variable, including brightness (male $\bar{x}=4968.8 \pm 339.1$; female $\bar{x}=5595.4 \pm$ 276.9), intensity (male $\bar{x}=18.18 \pm 1.38$; female $\bar{x}=21.06 \pm 1.13$ ), saturation (male $\bar{x}$ $=0.27 \pm 0.02$; female $\bar{x}=0.28 \pm 0.01$ ), and hue (male $\bar{x}=508.6 \pm 1.03 \mathrm{~nm}$; female $\bar{x}=$ $508.1 \pm 0.84 \mathrm{~nm}$ ). However, when these four variables were entered into a DFA with sex as the classification variable, we found a significant difference between the sexes (Wilks' lambda $=$ $\left.0.71, F_{4,30}=3.1, P=0.03\right)$. Colorimetric variables successfully identified the correct sex of $67 \%$ of the females and $79 \%$ of the males. Overall, the DFA correctly classified sex $43 \%$ better than by chance alone (Cohen's Kappa $=$ $0.43 \pm 0.15, Z=2.57, P=0.01)$.

\section{DISCUSSION}

Male Steere's Liocichla in our study tended to be larger than females, with greater mass and longer wings, tails, tarsi, and yellow facial patches. To our knowledge, there are no published studies of sexual dimorphism for other species in this genus, including the Red-faced Liocichla (Liocichla phoenicea) and the Emeishan Liocichla (Liocichla omeiensis). However, data from other timaliid babblers suggest that male-biased size dimorphism may be widespread in this group. For example, male Taiwan Yuhinas (Yubina brunneiceps) are larger than females (Yuan et al. 2006). Male-biased size dimorphism has also been reported in the Chestnutcapped Babbler (Timalia pileata) and sexual plumage dichromatism has been reported in Wren-babblers (Spelaeornis spp., Rasmussen and Anderton 2005).

Whether or not these traits are used by conspecifics in behavioral decisions regarding sex is unknown. However, because several characters 
differed significantly between the sexes, they could potentially signal an individual's sex. In addition, conspicuous traits significantly correlated with body size, such as the yellow facial patch, may be used by conspecifics, not only as an indicator of an individual's sex, but as a conspicuous proxy measure of overall body size that could potentially signal age, condition, or competitive ability. However, the considerable overlap between males and females in all of these traits suggests that no one trait alone would be an accurate indicator of sex.

We found no evidence that the yellow facial patch is proportionally larger in males and, therefore, no evidence that this plumage patch acts as a potential sexual ornament. However, the difference was nearly significant in $1 \mathrm{yr}$. The degree to which the facial spot is proportionately larger in males may be slight and thus undetectable given our sample size.

Two measures, culmen and patch length, varied significantly between years. This is likely due to measurement error associated with different field workers each year. These two measures were likely subject to such measurement variation because they were more difficult to measure consistently than other characters. For the culmen the proximal point where the measure begins can be difficult to define and thus is likely to vary between investigators (Winker 1998).

The shape of reflectance spectra for the yellow breast feathers of Steere's Liocichla suggests carotenoid deposition. The reflectance minima of reflectance curves near $450 \mathrm{~nm}$ match the absorption maxima of many carotenoid pigments (McGraw 2006), and the shape of the reflectance spectra in Steere's Liocichla closely matches that of species with known carotenoid-based plumage coloration (MacDougall and Montgomerie 2003, Mays et al. 2004). We found no significant differences between males and females in brightness, intensity, saturation, or hue. However, a DFA constructed with these variables revealed a significant difference between the sexes in color. The lack of significant differences in individual colorimetric variables may have resulted from low statistical power due to high variation in reflectance within the sexes. Although there was little evidence for sexual differences in hue or saturation, females tended to have higher reflectance than males. Because carotenoid concentration does not appear to influence brightness (Saks et al. 2003), our results 


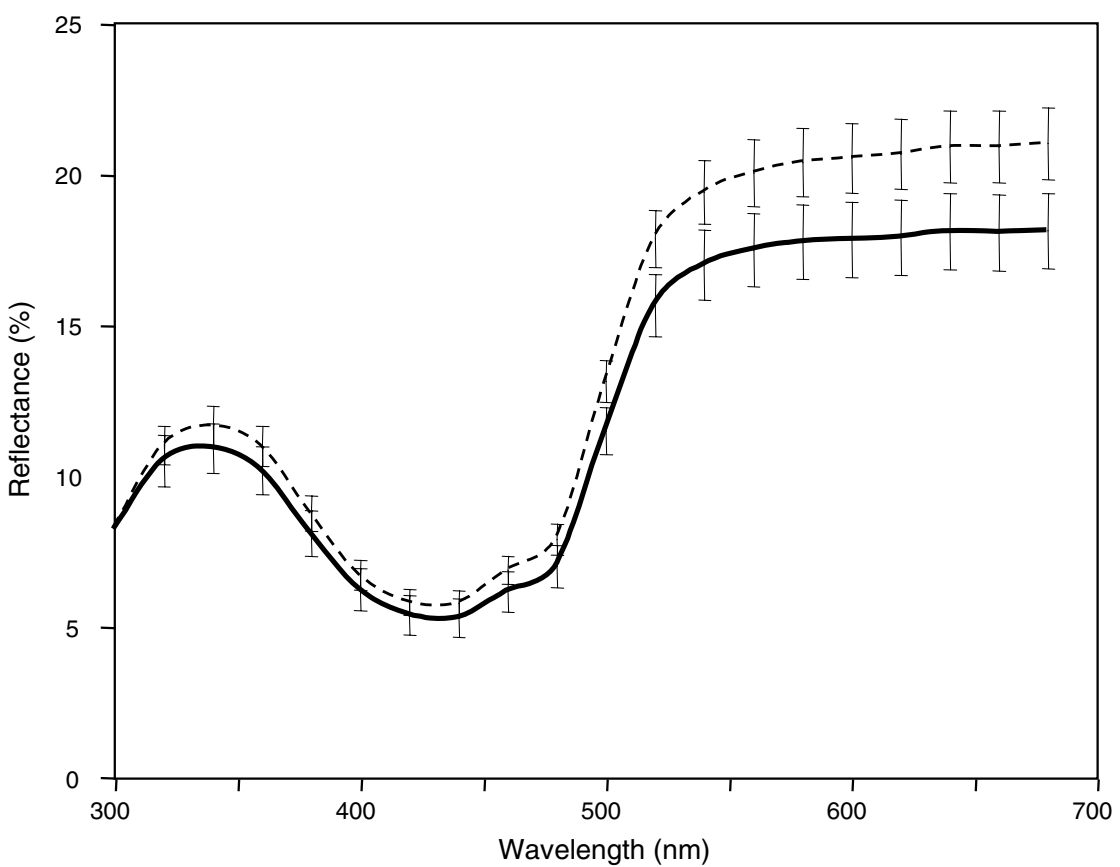

Fig. 1. Mean percent reflectance $\pm 1 \mathrm{SE}$ for female $(N=21$, dashed line) and male ( $N=14$, solid line) Steere's Liocichla.

suggest that the feathers of males and females differ in underlying microstructure (Mennill et al. 2003, Mays et al. 2004, Shawkey and Hill 2005), the number of melanized barbules present on feathers (Shawkey et al. 2005), or the concentration of melanin in the feathers (McGraw et al. 2004). More detailed studies of coloration in Steere's Liocichla are clearly warranted.

Body size and plumage variation may be correlated with age. Although we identified hatchingyear birds and eliminated them from this particular study, we had no means of accurately determining age after hatch year so we could not control for age effects post hatch year. Age may have confounded our results if morphological variation is correlated with age and one sex was consistently either older or younger than the other, perhaps due to differential survival between the sexes.

Our results suggest the potential for modest sexual selection operating in Steere's Liocichla. Males likely compete for mates and breeding territories. However, both sexes are territorial during the breeding season and defend territories against intruders (Lo 1987, Fang 2005, Mays et al. 2005). Female preferences for larger mates with more conspicuous plumage ornaments could also explain some of the sexual differences we documented.

The limited dimorphism in Steere's Liocichla relative to that exhibited by many temperate passerines can probably be best understood in the context of life history theory (Stutchbury and Morton 2001). More information concerning variation in male reproductive success and general breeding ecology is needed for Steere's Liocichla and other species to better elucidate how selection shapes the behavior, morphology, and breeding ecology of this and other tropical and subtropical species.

\section{ACKNOWLEDGMENTS}

We thank G. Hill for use of spectrometry equipment, B. Montgomerie for use of color analysis programs, and T. Hill for help with preparing feather samples for spectrometry. A. King provided help in the field and with genetic sexing. C.-F. Hsieh, Y.-L. Tsai, Y.-S. Weng, Y.-W. Peng, S.-F. Shen, and the staff of the National Taiwan University, Meifeng Horticultural Farm provided support in the field. Members of the Hill lab and three anonymous reviewers provided excellent comments. This work was supported by National Taiwan University, The Taiwan Endemic Species 
Research Institute, The National Science Council, and The National Science Foundation (grant no. 0307421).

\section{LITERATURE CITED}

Badyaev, A. V., AND G. E. Hill. 2003. Avian sexual dichromatism in relation to phylogeny and ecology. Annual Review of Ecology, Evolution, and Systematics 34: 27-49.

Barraclough, T. G., And P. H. Harvey. 1995. Sexual selection and taxonomic diversity in passerine birds. Proceedings of the Royal Society of London B 259: 211-215.

CiBois, A. 2003. Mitochondrial DNA phylogeny of babblers (Timaliidae). Auk 120: 35-54.

Collar, N. J. 1996. Family Otididae (Bustards). In: Handbook of birds of the world, vol. 3: hoatzin to auks. (J. del Hoyo, A. Elliott, and J. Sargatal, eds.), pp. 240-275. Lynx Edicions, Barcelona, Spain.

Cuthill, I. C., J. C. Partridge, A. T. D. Bennett, S. C. Church, N. S. Hart, and S. Hunt. 2000. Ultraviolet vision in birds. Advances in the Study of Behavior 29: 159-214.

DE JUANA, E. 1994. Family tetraonidae (Grouse). In: Handbook of birds of the world, vol. 2: new world vultures to guineafowl. (J. del Hoyo, A. Elliott, and J. Sargatal, eds.), pp. 376-411. Lynx Edicions, Barcelona, Spain.

EATON, M. D. 2005. Human vision fails to distinguish widespread sexual dichromatism among sexually "monochromatic" birds. Proceedings of the National Academy of Sciences 102: 10942-10946.

, AND S. M. LANYON. 2003. The ubiquity of avian ultraviolet plumage reflectance. Proceedings of the Royal Society of London B 270: 1721-1726.

FANG, W.-H. 2005. Abstracts of ornithological Master's theses from Taiwan, 1977-2003. Forktail 21: 99120.

Griffiths, R., M. C. Double, K. Orr, And R. J. G. DAWSON. 1998. A DNA test to sex most birds. Molecular Ecology 7: 1071-1075.

HART, N. S. 2001. The visual ecology of avian photoreceptors. Progress in Retinal and Eye Research 20: 675703.

Heinsohn, R., S. Legge, And J. A. Endler. 2005. Extreme reversed sexual dichromatism in a bird without sex role reversal. Science 309: 617-619.

LO, L.-C. 1987. A biological study of Liocichla steerii at Chitou area. M. S. thesis, National Taiwan University, Taipei, Taiwan.

MacDougall, A. K., and R. Montgomerie. 2003. Assortative mating by carotenoid- based plumage colour: a quality indicator in American Goldfinches, Carduelis tristis. Naturwissenschaften 90: 464-467.

MacKinnon, J., AND K. Phillipps. 2000. A field guide to the birds of China. Oxford University Press, Oxford, UK.

Mays, H. L., K. J. McGraw, G. Ritchison, S. CoOper, V. Rush, AND R. S. PARKer. 2004. Sexual dichromatism in the yellow-breasted Chat Icteria virens: spectrophotometric analysis and biochemical basis. Journal of Avian Biology 35: 125-134.

, C.-T. YAO, AND H.-W. YUAN. 2005. Antiphonal duetting in Steere's Liocichla (Liocichla steerii): male song individuality and correlation between habitat and duetting behavior. Ecological Research 21: 311314.

McGarigal, K., S. Cushman, and S. Stafford. 2000. Multivariate statistics for wildlife and ecology research. Springer-Verlag, New York.

MCGRAW, K. J. 2006. Mechanics of carotenoid-based coloration. In: Bird coloration, vol. 1: mechanisms and measurements (G. E. Hill and K. J. McGraw, eds.), Harvard University Press, Cambridge, MA.

, K. Wakamatsu, A. B. Clark, and K. Yasukawa. 2004. Red-winged blackbirds Agelaius phoeniceus use carotenoid and melanin pigments to color their epaulets. Journal of Avian Biology 35: 543-550.

Mennill, D. J., S. M. Doucet, R. Montgomerie, And L. M. RATClifFE. 2003. Achromatic color variation in black-capped Chickadees, Poecile atricapilla: black and white signals of sex and rank. Behavioral Ecology and Sociobiology 53: 350-357.

Milonoff, M., AND H. Linden. 1989. Sexual size dimorphism of body components in Capercaillie chicks. Ornis Scandinavica 20: 29-35.

Montgomerie, R. 2006. Analyzing colors. In: Bird coloration, vol. 1: mechanisms and measurements (G. E. Hill, and K. J. McGraw, eds.), Harvard University Press, Cambridge, MA.

Rasmussen, P. C., AND J. C. Anderton. 2005. Birds of South Asia: the Ripley guide. Lynx Edicions, Barcelona, Spain.

Rising, J. D., AND K. M. SOMERS. 1989. The measurement of overall body size in birds. Auk 106: 666-674.

Titus, K., J. A. Mosher, AND B. K. Williams. 1984. Chance-corrected classification for use in discriminant analysis: ecological applications. American Midland Naturalist 111: 1-7.

SAS InSTITUTE INC. 2003. JMP for Mac Release 5.0.1.2. SAS Institute Inc. Cary, NC.

SAKS, L., K. MCGRAW, AND P. HoraK. 2003. How feather colour reflects its carotenoid content. Functional Ecology 17: 555-561.

Seutin, G., B. N. White, and P. T. Boag. 1991. Preservation of avian blood and tissue samples for DNA analyses. Canadian Journal of Zoology 69: 82-90.

Shawkey, M. D., A. M. Estes, L. Siefferman, AND G. E. Hill. 2005. The anatomical basis of sexual dichromatism in non-iridescent, ultraviolet-blue structural coloration of feathers. Biological Journal of the Linnean Society 85: 259-271.

—, AND G. E. Hill. 2005. Carotenoids need structural colours to shine. Biology Letters 1: 121-124.

SPSS INC. 2002. SPSS for Windows Release 11.0.1. SPSS Inc. Chicago, IL.

Stutchbury, B. J. M., AND E. S. Morton. 2001. Behavioral ecology of tropical birds. Academic Press, San Diego, CA.

WINKER, K. 1998. Suggestions for measuring external characters of birds. Ornitologica Neotropical 9: 2330 .

YuAN, H.-W., S.-F. SHEN, AND H.-Y. HunG. 2006. Morphology and breeding chronology of joint-nesting Taiwan Yuhinas. Wilson Journal of Ornithology 118: 558-562. 